\title{
Determination of Economic Threshold level (ETL) of brown planthopper, Nilaparvata lugens Stal. population in different stages of rice crop at Raipur
}

RANDEEP KR KUSHWAHA*, SANJAY SHARMA AND PADMESH KUNDAN SHARMA

Department of Entomology, Indira Gandhi Agriculture University, RAIPUR (C.G.) INDIA

\section{ARITCLE INFO}

Received : 18.09 .2015

Revised : 13.02 .2016

Accepted : 27.02 .2016

\section{KEY WORDS :}

BPH, Nilaparvata lugens Stal., Determination of economic threshold Level, Different stages of rice

*Corresponding author:

Email: rndp2010@gmail.com

\begin{abstract}
Determination of Economic Threshold Level (ETL) was carried out at glass house of Entomology Dept., Indira Gandhi Krishi Vishwavidyalaya, Raipur, Chhattisgarh during 2012 and 2013. The five to ten BPH nymphs/hill attacked at seedling, fifteen to twenty at tillering and twenty to twenty five at booting stage can cause yellowing in lower leaves then wilting and death in the varieties TN-1, Swarna, Karma mahsuri and Mahamaya. However, the variety Ptb-33 is not affected because of its high level of resistance to BPH but Karma mahsuri was moderately susceptible as compared to TN1 but variety Mahamaya and Swarna noticed high level of susceptibility. Descending order of BPH infestations observed with the different varieties can be ranked as TN-1 $<$ Swarna < Mahamaya < Karma masuri < ptb-33 within seven day after nymph release.

How to view point the article : Kushwaha, Randeep Kr, Sharma, Sanjay and Sharma, Padmesh Kundan (2016). Determination of Economic Threshold level (ETL) of brown planthopper, Nilaparvata lugens Stal. population in different stages of rice crop at Raipur. Internat. J. Plant Protec., 9(1) : 115-119.
\end{abstract}

